\title{
ChemComm
}

\section{Chirality meets visible-light photocatalysis in a molecular cerium vanadium oxide cluster $\dagger$}

Cite this: Chem. Commun., 2014

50, 1827

Received 19th November 2013

Accepted 12th December 2013

DOI: $10.1039 / c 3 c c 48834 a$

www.rsc.org/chemcomm

\author{
Andrey Seliverstov ${ }^{\mathrm{ab}}$ and Carsten Streb*ab
}

The first example of a molecular cerium vanadium oxide photocatalyst is presented. A cerium vanadium oxide cluster, $\left(n \mathrm{Bu}_{4} \mathrm{~N}\right)_{2}$ $\left[\left(\mathrm{Ce}(\mathrm{dmsO})_{3}\right)_{2} \mathrm{~V}^{\mathrm{IV}} \mathrm{V}^{\mathrm{V}}{ }_{11} \mathrm{O}_{33} \mathrm{Cl}\right] \times 2 \mathrm{DMSO}$ (1), was obtained by bottom-up self-assembly. The compound exhibits high visible-light photooxidative activity towards indigo with quantum efficiencies $>10 \%$. Initial mechanistic studies of the photooxidation reaction are presented. The structure of compound 1 is based on chiral, $C_{2}$-symmetric cluster anions and both enantiomers are present in the crystal lattice. Retrosynthetic analysis suggests that chiral building blocks are spontaneously formed by symmetry breaking during self-assembly. The assembly of 1 based on the chiral building blocks is discussed conceptually. Consequences of this assembly mechanism for the development of chiral molecular catalysts and photocatalysts are described.

Chirality, or handedness, is a universal concept found in natural and synthetic chemical systems. ${ }^{1}$ Chiral compounds are vital for life and many biological processes rely on the presence of one enantiomer only. ${ }^{2}$ Thus the development of homogeneous catalytic systems which selectively yield one specific enantiomer (so-called enantioselective or asymmetric catalysis) is a main thrust in modern academic and industrial research. ${ }^{3}$ In coordination compounds, catalyst chirality is often introduced through chiral organic ligands, giving facile access to enantioselective catalysts. ${ }^{4}$ In contrast, for purely inorganic compounds, virtually no homogeneous chiral catalysts are known. Prime candidates for inorganic asymmetric catalysis $^{5}$ are molecular metal oxides, so-called polyoxometalates (POMs). POMs are early transition-metal oxo anions formed spontaneously in solution by self-assembly. ${ }^{6}$ Over recent years, several chiral POMs were reported wherein chirality is intrinsic to the

\footnotetext{
${ }^{a}$ Institute of Inorganic Chemistry I, Ulm University, Albert-Einstein-Allee 11, 89081 Ulm, Germany. E-mail: carsten.streb@uni-ulm.de; Fax: +49-731-50-23039; Tel: +49-731-50-23867

${ }^{b}$ Department Chemistry and Pharmacy, Inorganic Chemistry II, Friedrich-Alexander-University Erlangen-Nuremberg, Egerlandstr. 1, 91058 Erlangen, Germany

$\dagger$ Electronic supplementary information (ESI) available: Synthetic, analytical, crystallographic and photocatalytic details. CCDC 959107. For ESI and crystallographic data in CIF or other electronic format see DOI: 10.1039/c3cc48834a
}

cluster framework, thereby laying the principal foundation for asymmetric POM catalysis. ${ }^{7,8}$ In addition, POM catalysts can be driven by light as their photocatalytic activity has been pioneered by the groups of Hill, ${ }^{9}$ Papaconstantinou, ${ }^{10}$ Yamase $^{11}$ and others: ${ }^{12}$ under UV-light irradiation, tungsten- and molybdenum-based POMs have been used for organic oxidations, epoxidations and C-H-activations. ${ }^{9,12}$ Currently, efforts are underway to push the light absorption of POMs into the visible range so as to access sunlightdriven photocatalytic systems. ${ }^{13-15}$

To this end, we have set out to combine the benefits of POMs outlined above and investigate whether chiral visible-light-driven POM photocatalysts can be accessed. Based on previous studies, ${ }^{12}$ we employed vanadium-oxide based clusters ${ }^{16,17}$ due to their enhanced visible-light photoactivity compared with molybdates and tungstates. ${ }^{13-15}$ Furthermore, we hypothesized that the reversible assembly of reactive vanadate fragments under self-assembly conditions ${ }^{16-18}$ could lead to the spontaneous formation of chiral fragments. ${ }^{19}$ The concept is based on a recent report by Cronin et al., who used a related approach for the assembly of chiral "Möbius-strip" molybdate clusters. ${ }^{20}$ In recent work we have outlined that reactive vanadate fragments can be assembled into stable clusters by a simultaneous reaction with metal cation linkages and template anions. ${ }^{15,21}$ Here this approach is employed by introducing cerium(III) linkages and chloride templates to access a chiral molecular cerium vanadium oxide cluster, see Fig. 1 . Therefore, this study opens new avenues for the design, development and application of chiral inorganic photocatalysts.

Compound 1 is obtained by the reaction of $\left(n \mathrm{Bu}_{4} \mathrm{~N}\right)_{3}\left[\mathrm{H}_{3} \mathrm{~V}_{10} \mathrm{O}_{28}\right]$, $\mathrm{CeCl}_{3} \times 7 \mathrm{H}_{2} \mathrm{O}$ and aqueous $n \mathrm{Bu}_{4} \mathrm{NOH}$ solution in dimethylsulfoxide (DMSO) at $T=80{ }^{\circ} \mathrm{C}$. Brown single-crystals of $\mathbf{1},\left(n \mathrm{Bu}_{4} \mathrm{~N}\right)_{2}[(\mathrm{Ce}-$ $\left.\left.(\mathrm{dmso})_{3}\right)_{2} \mathrm{~V}^{\mathrm{IV}} \mathrm{V}^{\mathrm{V}}{ }_{11} \mathrm{O}_{33} \mathrm{Cl}\right] \times 2 \mathrm{DMSO}\left(=\left(n \mathrm{Bu}_{4} \mathrm{~N}\right)_{2} \mathbf{1 a} \times 2 \mathrm{DMSO}\right)$ were obtained in yields of $c a$. 25\%. Single-crystal X-ray diffraction shows that compound $\mathbf{1}$ crystallizes in the monoclinic space

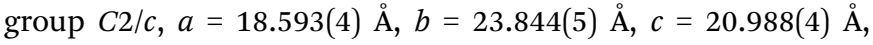
$\beta=95.24(3)^{\circ} \neq$ The cluster anions in 1 possess a chloridetemplated, tetradecanuclear cluster consisting of twelve vanadium centers and two cerium centers. The cerium centers are located on opposite cluster faces. The vanadium oxide cluster shell, 


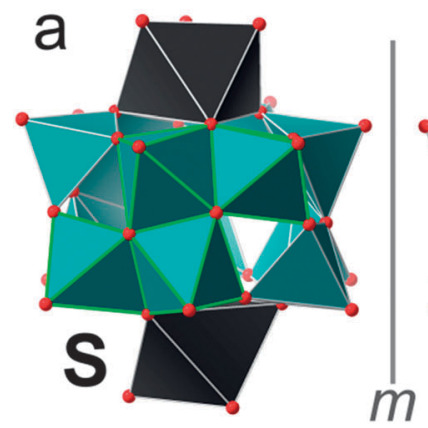

$m$
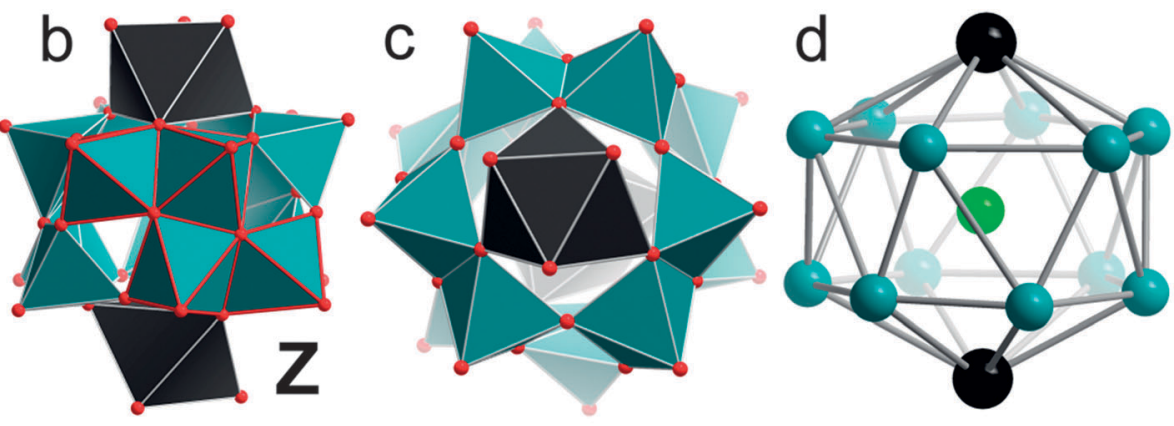

Fig. 1 Illustration of the chiral cerium vanadium oxide cluster $1 \mathrm{a},\left[\left(\mathrm{Ce}(\mathrm{dmsO})_{3}\right)_{2} \mathrm{~V}_{12} \mathrm{O}_{33} \mathrm{Cl}^{2-}\right.$. (a) and (b) Polyhedral side view of the $S$ - and $Z$-enantiomer observed in the lattice of 1 . The $C_{2}$-symmetric $\left\{V_{4}\right\}$ building units are highlighted in green $(S)$ and red $(Z)$ outline. (c) Top view of $1 a$, showing the $\left\{V_{6}\right\}$ binding site assembled from three corner-sharing $\left\{V_{2}\right\}$ units. (d) Metal-only framework of $1 \mathrm{a}$, highlighting the distorted hexagonal antiprismatic arrangement of the vanadium centres and the binding sites of the cerium centres. Colour scheme: V: teal; Ce: black; Cl: green; O: red. Only the coordinating oxygen atoms of the DMSO ligands are shown for clarity.

$\left[\mathrm{V}_{12} \mathrm{O}_{33} \mathrm{Cl}\right]^{8-}$, is barrel-shaped and all $\mathrm{V}$ ions are in a square pyramidal $\left[\mathrm{VO}_{5}\right]$ coordination environment. The twelve vanadium centers are arranged in two planar, hexagonal rings and adopt a distorted hexagonal antiprismatic arrangement, resulting in a chiral cluster architecture, see Fig. 1 . The cluster shell is assembled from three tetranuclear, Z- or S-shaped $\left\{\mathrm{V}_{4}\right\}$ building units formed by edge-shared linkage of two $\left\{\mathrm{V}_{2}\right\}$ moieties. Linkage of three $\left\{\mathrm{V}_{4}\right\}$ units around a central chloride template gives rise to the formation of two cluster enantiomers. Due to the $C_{2}$ symmetry of the $\left\{\mathrm{V}_{4}\right\}$ units, the cluster anion 1a is also $C_{2}$-symmetric and thus chiral. In the lattice of 1 , both enantiomers (labeled $Z$ - and $S$-enantiomer, see Fig. 1 and ESI $\dagger$ ) are observed in a $1: 1$ ratio so that 1 crystallizes as a racemate. To the best of our knowledge, this is only the second example of a non-polymeric chiral vanadium oxide cluster and the first example of a heterometallic chiral polyoxovanadate: in 2009, the first chiral polyoxovanadate, $\left[\mathrm{V}_{18} \mathrm{O}_{46}\left(\mathrm{NO}_{3}\right)\right]^{5-}$, was reported by Hayashi et $\mathrm{al}^{22}$ In addition, several vanadate-based polymeric helices have been reported, most notably an enantiomerically pure, helical coordination polymer discovered by Zubieta et al. ${ }^{23}$

It should be noted that the chirality of $\mathbf{1 a}$ is not helical chirality $^{23}$ nor distortion chirality ${ }^{7}$ (chirality caused by alternating bond lengths) which are two common chirality modes observed in POMs. ${ }^{78}$ Instead, the chirality in $\mathbf{1 a}$ is a consequence of the $C_{2}$-symmetry and the non-planar, convex structure of the $\left\{\mathrm{V}_{4}\right\}$ building blocks (inherent chirality). ${ }^{7,8}$ Retrosynthetic structural analysis led us to propose the following assembly scheme based on spontaneous symmetry breaking: ${ }^{20}$ achiral $\left\{\mathrm{V}_{2}\right\}$ units can be linked to give either $Z-\left\{\mathrm{V}_{4}\right\}$ or $S-\left\{\mathrm{V}_{4}\right\}$ units, thus offering a feasible route for the generation of both chiral building blocks, see Fig. 2 .

As no chiral auxiliaries are present, both $\left\{\mathrm{V}_{4}\right\}$ enantiomers are formed with identical probability. In consequence, equal amounts of $Z$ - and $S-\left\{\mathrm{V}_{4}\right\}$ are formed and thus a racemic mixture of the $Z$ - and $S$-cluster enantiomers is obtained. This is confirmed by crystallographic analysis which reveals that the unit cell of 1 contains a 1:1 molar ratio of the enantiomers. This observation may serve as a foundation for the enantioselective self-assembly of POMs where one chiral building unit is selectively stabilized (and thus amplified) using chiral auxiliary ligands.

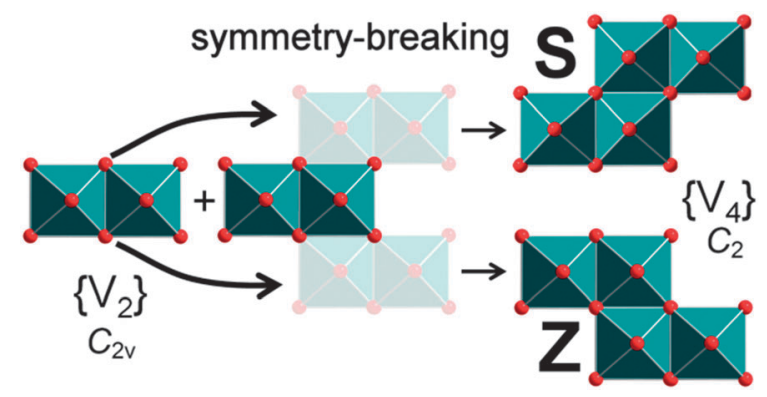

Fig. 2 A proposed assembly scheme for the chiral $Z$ - and $S-\left\{V_{4}\right\}$ units by spontaneous symmetry-breaking. Achiral $\left\{V_{2}\right\}$ units (left) are linked to give both $\left\{V_{4}\right\}$ units with identical formation probability. Color scheme: V: teal; O: red.

Cerium coordination in 1a is accomplished by two hexagonal $\left\{\mathrm{V}_{6}\right\}\left(=\left\{\mathrm{V}_{2}\right\}_{3}\right)$ rings formed by corner-sharing linkage of three linear $\left\{\mathrm{V}_{2}\right\}$ units. The binding sites are located on the top and bottom face of the hexagonal antiprism. Each cerium forms three $\mathrm{V}-\mathrm{O}-\mathrm{Ce}$ coordination bonds and further coordinates three DMSO ligands, giving a distorted octahedral coordination environment. The cluster anion of 1a is observed using cryospray-ionization mass spectrometry (CSI-MS) at $\mathrm{m} / \mathrm{z} 726.98$ (calcd 726.97), assigned as $\left\{\left[\mathrm{Ce}_{2} \mathrm{~V}_{12} \mathrm{O}_{33} \mathrm{Cl}\right]^{2-}\right\}$, see ESI. $\dagger$

Charge balance considerations suggest that 1a has one reduced $\mathrm{V}^{\mathrm{IV}}$ center. This is also supported by UV-VIS-NIR spectroscopy where a broad, characteristic inter-valence chargetransfer (IVCT) transition is observed at $\lambda_{\max }=875 \mathrm{~nm}, \varepsilon=1.21 \times$ $10^{3} \mathrm{M}^{-1} \mathrm{~cm}^{-1} \cdot{ }^{18}$ BVS calculations suggest the presence of a delocalized $\mathrm{V}^{\mathrm{IV}}$ center $(\mathrm{BVS}(\mathrm{V})=4.97 \pm 0.08, \mathrm{BVS}(\mathrm{Ce})=3.15) .{ }^{24}$ The spontaneous reduction of vanadate precursors and the formation of $\mathrm{V}^{\mathrm{IV}}$ containing species upon heating are welldocumented in the literature. ${ }^{18}$

Compound 1 shows light absorption in the visible range up to $c a .540 \mathrm{~nm}$. Homogeneous photooxidative test reactions were therefore performed to evaluate the visible-light photocatalytic performance of 1 . In the test reactions (photooxidative dye degradation, substrate: indigo (Ind), solvent: DMF, [Ind]:[1] = 5:1, irradiation with monochromatic light (LED), $\lambda_{\max }=405 \mathrm{~nm}$ ), 1 showed 


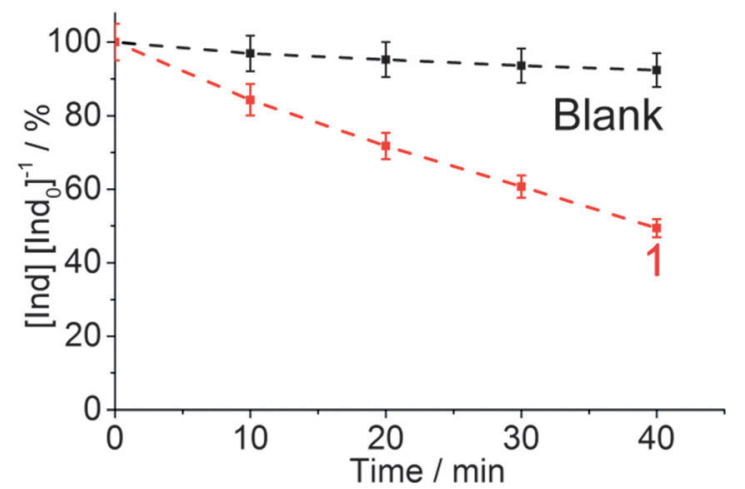

Fig. 3 Visible-light-driven dye photooxidation catalyzed by 1 . Solvent: DMF; dye: indigo (Ind); molar ratio [Ind]/[cluster] = $5: 1$; light source: LED, $\lambda_{\max }=405 \mathrm{~nm}$. Blank: indigo degradation in the absence of any photocatalyst.

promising photooxidative activity, see Fig. 3. Under the given reaction conditions, pseudo zeroth-order kinetics were found, the observed rate constant was $k_{\mathrm{obs}, 1}=3.62 \times 10^{-5} \mathrm{~mol} \mathrm{~L}^{-1} \mathrm{~min}^{-1}$; quantum efficiencies ${ }^{25}$ of $\phi \mathrm{ca} .10 .7 \%$ and turnover frequencies (TOF) of $c a .4 .80 \mathrm{~h}^{-1}$ were found. Initial mechanistic studies show that no change in photoreactivity is observed in the presence of a hydroxyl radical scavenger (EtOH), suggesting that no hydroxyl-mediated photooxidation mechanism is observed for 1 (see ESI $\dagger$ ). ${ }^{12}$ Comparative photooxidation reactions using isovanadates $\left[\mathrm{H}_{3} \mathrm{~V}_{10} \mathrm{O}_{28}\right]^{3-}$ and $\left[\mathrm{V}_{4} \mathrm{O}_{12}\right]^{4-}$ as reference samples show that in the visible range, compound 1 exhibits photoactivity in a comparable range to $\left[\mathrm{H}_{3} \mathrm{~V}_{10} \mathrm{O}_{28}\right]^{3-}$ and both clusters exhibit higher photoactivity than that of the $\left[\mathrm{V}_{4} \mathrm{O}_{12}\right]^{4-}$ unit (see ESI $\dagger$ ). The results are a first proof of principle which show that in principle, visible-light-driven photocatalysis by chiral cerium vanadium oxide clusters is possible.

In summary, we report a concise synthetic route which yields the first homogeneous chiral polyoxometalate photocatalyst. It is shown that the compound exhibits high visible-light photoactivity and quantum efficiencies $>10 \%$ are reported. The cluster chirality is rationalized based on the underlying, S- and Z-shaped, $C_{2}$-symmetric building blocks and we suggest a plausible mechanism for the spontaneous formation of chiral clusters under self-assembly conditions.

Future work will focus on separation of cluster enantiomers to develop homochiral asymmetric photocatalysts. Enantiomer stability will be studied experimentally and computationally. Catalytic studies on selective organic oxidations with a focus on asymmetric alcohol oxidations will be conducted. Furthermore, mechanistic, photophysical and theoretical studies will be used to rationalize the high visible light photoactivity of $\mathbf{1}$. Synthetic efforts will be focused on expanding the structural variety of the compound family.
The authors gratefully acknowledge Prof. I. Ivanović-Burmazović, R. Brachvogel and O. Tröppner (CSI-MS), Prof. P. Wasserscheid, Dr N. Taccardi (ICP); S. Bajus and P. Preuster (TGA) and Dr F. W. Heinemann for crystallographic discussions. A.S. gratefully acknowledges the Deutscher Akademischer Austauschdienst DAAD for a doctoral fellowship. C.S. gratefully acknowledges the Fonds der Chemischen Industrie FCI for a Liebig-Fellowship. This work was financially supported by Ulm University and FriedrichAlexander-University Erlangen-Nuremberg.

\section{Notes and references}

$\ddagger \mathrm{C}_{48} \mathrm{H}_{120} \mathrm{Ce}_{2} \mathrm{ClN}_{2} \mathrm{O}_{41} \mathrm{~S}_{8} \mathrm{~V}_{12}\left(M_{\mathrm{r}}=2564.90\right)$ : monoclinic, space group $C 2 / c$ (no. 15), $a=18.593(4) \AA, b=23.844(5) \AA, c=20.988(4) \AA, \beta=95.24(3)^{\circ}$, $V=9266(3) \AA^{3}, Z=4, T=150(2) \mathrm{K}, \mu(\mathrm{MoK} \alpha)=2.397 \mathrm{~mm}^{-1}, D_{\text {calc }}=$ $1.839 \mathrm{~g} \mathrm{~mm}^{-3}, 74694$ reflections measured $(5.572 \leq 2 \Theta \leq 53.002)$, 9600 unique $\left(R_{\text {int }}=0.0373\right)$ which were used in all calculations. The final $R_{1}$ was $0.0267(I>2 \sigma(I))$ and $\mathrm{w} R_{2}$ was 0.0758 (all data). CCDC 959107 contains the supplementary crystallographic data for $\mathbf{1}$.

1 R. S. Cahn, C. Ingold and V. Prelog, Angew. Chem., Int. Ed. Engl., 1966, 5, 385-415.

2 D. G. Blackmond, Philos. Trans. R. Soc. London, Ser. B, 2011, 366, 2878-2884.

3 R. Noyori, Angew. Chem., Int. Ed., 2002, 41, 2008-2022.

4 J. Halpern and B. Trost, Proc. Natl. Acad. Sci. U. S. A., 2004, 101, 5347.

5 W. Adam, P. L. Alsters, R. Neumann, C. R. Saha-Möller, D. SlobodaRozner and R. Zhang, J. Org. Chem., 2003, 68, 1721-1728.

6 L. Cronin and A. Müller, Chem. Soc. Rev., 2012, 41, 7333.

7 D.-Y. Du, L.-K. Yan, Z.-M. Su, S.-L. Li, Y.-Q. Lan and E.-B. Wang, Coord. Chem. Rev., 2013, 257, 702-717.

8 B. Hasenknopf, K. Micoine, E. Lacôte, S. Thorimbert, M. Malacria and R. Thouvenot, Eur. J. Inorg. Chem., 2008, 5001-5013.

9 C. L. Hill, in Comprehensive Coordination Chemistry II, ed. J. A. McCleverty and T. J. Meyer, Pergamon, Oxford, 2003, pp. 679-759.

10 E. Papaconstantinou, Chem. Soc. Rev., 1989, 18, 1.

11 T. Yamase, Catal. Surv. Asia, 2003, 7, 203-217.

12 C. Streb, Dalton Trans., 2012, 41, 1651.

13 J. Forster, B. Rösner, M. M. Khusniyarov and C. Streb, Chem. Commun., 2011, 47, 3114.

14 J. Tucher, Y. Wu, L. C. Nye, I. Ivanovic-Burmazovic, M. M. Khusniyarov and C. Streb, Dalton Trans., 2012, 41, 9938.

15 J. Tucher, L. C. Nye, I. Ivanovic-Burmazovic, A. Notarnicola and C. Streb, Chem.-Eur. J., 2012, 18, 10949-10953.

16 A. Müller, M. Penk, R. Rohlfing, E. Krickemeyer and J. Döring, Angew. Chem., Int. Ed. Engl., 1990, 29, 926-927.

17 A. Müller, R. Rohlfing, E. Krickemeyer and H. Bögge, Angew. Chem., Int. Ed. Engl., 1993, 32, 909-912.

18 (a) A. Müller, M. Penk, R. Rohlfing, E. Krickemeyer and J. Döring, Angew. Chem., Int. Ed. Engl., 1990, 29, 926-927; (b) K. Kastner and C. Streb, Chem. Commun., 2013, 49, 140-142.

19 Y. Hou, X. Fang and C. L. Hill, Chem.-Eur. J., 2007, 13, 9442-9447.

20 H. Zang, H. N. Miras, J. Yan, D.-L. Long and L. Cronin, J. Am. Chem. Soc., 2012, 134, 11376-11379.

21 J. Forster, B. Rösner, R. H. Fink, L. C. Nye, I. Ivanovic-Burmazovic, K. Kastner, J. Tucher and C. Streb, Chem. Sci., 2013, 4, 418-424.

22 K. Domae, D. Uchimura, Y. Koyama, S. Inami, Y. Hayashi, K. Isobe, H. Kameda and T. Shimoda, Pure Appl. Chem., 2009, 81, 1323-1330.

23 V. Soghomonian, Q. Chen, R. C. Haushalter, J. Zubieta and C. J. O'Connor, Science, 1993, 259, 1596-1599.

24 A. S. Wills, VaList, Program available from www.ccp14.ac.uk, 2010.

25 U. Megerle, R. Lechner, B. König and E. Riedle, Photochem. Photobiol. Sci., 2010, 9, 1400 . 